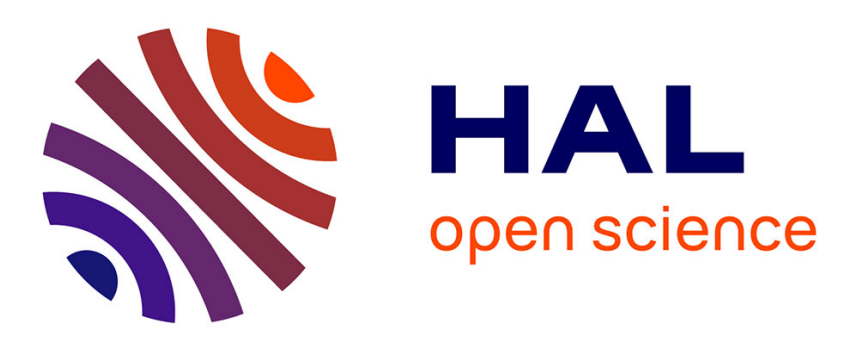

\title{
Effects of the dilatancy of joints and of the size of the building blocks on the mechanical behavior of masonry structures
}

Michele Godio, Ioannis Stefanou, Karam Sab

\section{- To cite this version:}

Michele Godio, Ioannis Stefanou, Karam Sab. Effects of the dilatancy of joints and of the size of the building blocks on the mechanical behavior of masonry structures. Meccanica, 2017, 10.1007/s11012017-0688-z . hal-01525275

\section{HAL Id: hal-01525275 \\ https://hal.science/hal-01525275}

Submitted on 19 May 2017

HAL is a multi-disciplinary open access archive for the deposit and dissemination of scientific research documents, whether they are published or not. The documents may come from teaching and research institutions in France or abroad, or from public or private research centers.
L'archive ouverte pluridisciplinaire HAL, est destinée au dépôt et à la diffusion de documents scientifiques de niveau recherche, publiés ou non, émanant des établissements d'enseignement et de recherche français ou étrangers, des laboratoires publics ou privés. 


\title{
Effects of the dilatancy of joints and of the size of the building blocks on the mechanical behavior of masonry structures
}

\author{
Michele Godio • Ioannis Stefanou - Karam Sab
}

Received: date / Accepted: date

\begin{abstract}
The effect of the dilatancy of masonry interfaces and of the size of the building blocks on the strength of masonry structures is quantified herein. The study focuses mainly on out-of-plane loadings, which can appear due to various factors such as wind, earthquakes or explosions. The analysis is performed using the Discrete Element Method (DEM), which allows to access directly various micro-mechanical parameters, such as the joints dilatancy angle and the size of the building blocks. Detailed DEM numerical models of existing experimental configurations are presented. The numerical results are first compared and validated towards the experimental observations and then they are used to derive qualitative and quantitative conclusions regarding the effects of joints dilatancy and blocks size. It is shown that dilatancy plays an important role on the overall strength of masonry even under low confinement. The size of the blocks is also an important
\end{abstract}

\section{Godio}

Earthquake Engineering and Structural Dynamics Laboratory (EESD), School of Architecture, Civil and Environmental Engineering (ENAC), Ecole Polytechnique Fédérale de Lausanne (EPFL)

EPFL ENAC IIC EESD, GC B2 495, Station 18, CH-1015

Lausanne, Switzerland

E-mail: michele.godio@epfl.ch

I. Stefanou (corresponding author)

Université Paris-Est, Laboratoire Navier (UMR 8205), CNRS, ENPC, IFSTTAR

F-77455 Marne-la-Vallée cedex 2, France

E-mail: ioannis.stefanou@enpc.fr

K. Sab

Université Paris-Est, Laboratoire Navier (UMR 8205), CNRS, ENPC, IFSTTAR

F-77455 Marne-la-Vallée cedex 2, France

E-mail: karam.sab@enpc.fr parameter that needs to be considered in the modeling of masonry structures.

Keywords Dilatancy · Scale effect · Masonry · Discrete Element Method · Experimental tests · Limit analysis

\section{Introduction}

Masonry is a composite material made of discrete building blocks that are quasi-periodically arranged in space. The masonry blocks interact through their interfaces (or joints), where mortar might be present or not (dry masonry). The mechanical behavior of the masonry joints plays an important role as far as it concerns the overall strength and failure of a masonry structure. This is especially true in the shear-tensional and in the shearcompressional regime, where experimental observations show that failure is localized to the joints. This result is corroborated also by theoretical investigations (e.g. [50]), which show that the failure of the building blocks is important only under high compression.

Besides the ultimate shear strength of masonry joints, of particular importance is their dilatancy. Masonry joints, show generally a non-dilatant behavior. For instance, monotonic and cyclic shear tests of masonry interfaces $[39,30]$ show zero dilatancy, even though the friction angle remains high, and in some cases constant, during sliding. This contrast between the values of the friction and dilatancy angles is typical in geomaterials (see for example various kinds of sands, soils and rocks) and violates the classical and handy assumption of associativity in the theory of plasticity.

Another aspect that seems to influence the overall strength of masonry structures is the size of the building blocks. This inherent scale effect is known to have a 
direct impact on the dynamics of articulated masonry structures $[23,31,53,16,32,48]$. However, less evidence exists for the strength of masonry under quasi-static loading (see [41] for a recent review).

In this paper we investigate both the effect of the dilatancy of the joints and of the size of the building blocks on the mechanical behavior of masonry structures. We particularly focus on out-of(the masonry)plane actions, which can be responsible for partial or total collapse. This kind of loads might be due to wind, earthquakes or explosions [55], among others.

The above mentioned investigation is performed using the Discrete Element Method (DEM), which allows to access directly the various micro-mechanical parameters such as the joints dilatancy angle and the size of the building blocks. With the price of increased calculation time, detailed numerical models of existing experimental configurations are presented. The numerical results are first compared and validated towards experimental observations and then are used to derive qualitative and quantitative conclusions regarding the effects of joints dilatancy and blocks size (also called scale effect in this work).

It is worth emphasizing that experimental tests for studying in detail the mechanical behavior of masonrylike materials are quite difficult to perform in practice. Indeed, it is difficult to measure and control experimentally the mechanical parameters of the masonry constituents, the heterogeneities and other uncertainties, the exact thickness of the joints, the water to cement ratio in case of mortared joints due to suction phenomena, the exact boundary conditions, the specimen preparation procedure and many other factors. For this reason, the use of the DE method has been expanding in this field the last decades (e.g. [15, 17, 2, 8, 26, 28, 40,47, 49] among many others), also supported by a growing computational power.

The paper is structured as follows. Section 2 presents the main modeling assumptions of the DEM model used in the paper. The constitutive law used for the joints is presented and the level of discretization in the contact representation is investigated numerically and discussed. Section 3 validates the DEM models against results from experimental tests taken from the literature. These tests are representative of both dry stone masonry and mortar/brick masonry. Section 4 closes the paper, studying the effect of joints dilatancy and the evidence of scale effects in the out-of-plane failure of masonry.

\section{Modeling assumptions}

Each modeling strategy has its advantages and drawbacks. DEM modeling seems to be better adapted to the investigation presented in this paper, as it allows to control directly several micromechanical parameters, such as the constitutive behavior of the joints and the geometry of the building blocks. Moreover, it allows to simulate the progressive failure of masonry and capture with increased fidelity the post-peak, softening, dynamic behavior of a masonry structure. Notice that at this stage large displacements and rotations take place, which most DEM codes are able to capture. The above aspects are of particular importance for the out-of-plane deformation and failure of masonry.

The DEM simulations were carried out by means of the 3DEC software [24, 3DEC 5.0]. A conditionally stable central finite differences scheme is used in this code for integrating in time the equations of motion of each block. Due to the inherent, dynamic character of most DEM codes, including 3DEC, care was taken in order to assure quasi-static conditions until failure. The loads were applied adequately slow in order to assure a small ratio of the kinetic energy over the total energy of the system.

Under relatively low compression loads, the deformation is principally concentrated at the interfaces of the blocks [50]. Therefore, it is a reasonable assumption to consider the blocks as rigid with deformable interfaces/joints (soft-contacts assumption). This assumption is common in literature for discrete blocky/granular structures and removes the indeterminacy of the system (e.g. $[6,33,11,9,10])$. The comparison with experimental results, presented in the following sections, corroborates this assumption.

\subsection{Constitutive behavior of masonry joints}

In the absence of more detailed experimental data regarding the constitutive behavior of masonry joints the Coulomb criterion seems to be a reasonable choice. Several experimental observations (e.g. [39, 42,30,43]) justify its use up to moderate compression. More specifically, the maximum joint shear (or tangential) force $t_{t}$ is limited by the Coulomb failure surface:

$F_{1}=t_{t}-C-t_{n} \operatorname{Tan}[\Phi] \leq 0$

where $C$ is the cohesion of the interface, $\Phi$ the friction angle and $t_{n}$ the normal force. Compression is considered negative. In shear/tensional regime a tension cutoff is often used as shown in Figure 1. In other words, the maximum joint normal force $t_{n}$ is limited by the 
tensile strength according to:

$F_{2}=t_{n}-f_{t} \leq 0$

where $f_{t}$ is the maximum tensile strength of the interface.

The above two inequalities define the elastic domain of a masonry interface. These surfaces can evolve and contract under combined shear and normal plastic deformation in order to take into account various micromechanisms related to progressive damage of the joint. According to experimental results on interfaces, a softening behavior is observed as depicted in Figure 1. In this way the cohesion, the maximum tensile strength and the friction and dilatancy angles can evolve from their initial values $c_{i n i}, f_{t, i n i}, \Phi_{i n i}, \Psi_{i n i}$ to some smaller residual values $c_{r e s}, f_{t, r e s}, \Phi_{\text {res }}, \Psi_{\text {res }}$. All these values can be determined by typical experimental tests on interfaces.

Regarding the plastic flow rule, this is given by the following potential:

$$
\begin{array}{r}
G_{1}=t_{t}-c-t_{n} \operatorname{Tan}[\Psi] \\
G_{2}=t_{n}-f_{t}
\end{array}
$$

where $\Psi$ is the dilatancy angle. If $\Psi=\Phi$ then we say that the plastic flow rule is associative (normality condition).

Finally, a small damping is considered at the level of the joints in order to dissipate oscillations and reach equilibrium fast.

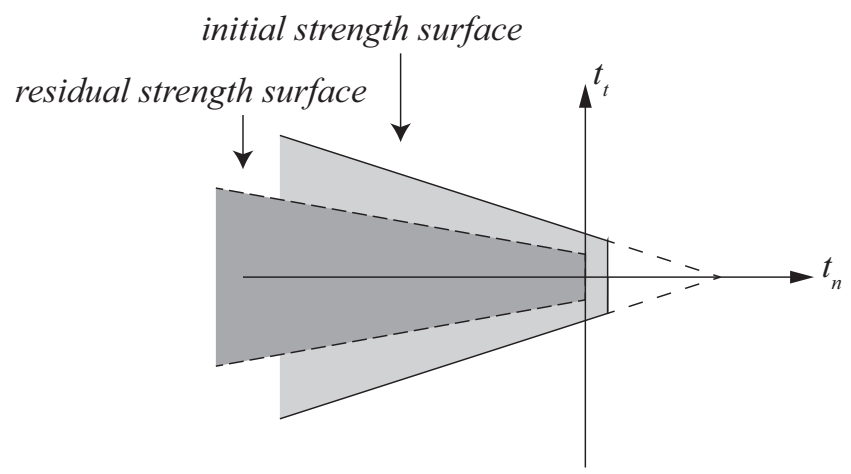

Fig. 1: Initial and residual strength surfaces used for modeling joints behavior.

\subsection{Contact discretization}

Contact discretization plays a fundamental role in the representation of the response of masonry structures when modeled with the Discrete or the Finite Element Method [27,24]. As far it concerns the specific DEM code used herein, 3DEC, the number of contact points situated across the wall thickness has a direct impact on the model response. This is especially important for out-of-plane loads as the one applied in the following sections. In this situation the contacts should be finely descritized [27].

The number of contact points across the wall thickness (contact discretization) depends on the geometrical properties of the model, such as the shape, the size, the degree of interlocking of the blocks that compose the wall and the constitutive assumptions. A significant number of contact points may be required when modelling the flexural modes of a masonry wall at high frequencies [22] or when interested in representing its torsional-flexural elastoplastic behavior [21].

In order to determine the minimum number of points in contact discretization that are necessary for performing reliable simulations with 3DEC, a convergence analysis is carried out in this paragraph. In particular, a masonry wallette made of 3 X 13 blocks is laid on a rigid base support and is laterally supported by a masonry column where blocks translation is prevented (Rondolet's type test Figure 2). Two different loads are applied in two stages. At the first stage, a gravity load is applied and the system is left to reach equilibrium. At the second stage, increasing out-of-plane forces, proportional to the block mass, are applied to each block, up to wall failure. The maximum proportionality factor, $\Lambda^{D E}$, is defined as the maximum ratio of the horizontal, $R_{h}$, over the vertical, $R_{v}$, reaction forces, measured at the lateral masonry column and at the base of the wall:

$\Lambda^{\mathrm{DE}}=\operatorname{Max}\left[\frac{R_{h}}{R_{v}}\right]$

Notice, that the maximum proportionality factor provides the collapse load multiplier.

Table 1: Material properties and geometry for Rondelet's-type tests.

\begin{tabular}{llll}
\hline geometry & \multicolumn{3}{c}{ joint properties } \\
\hline block width & $210 \mathrm{~mm}$ & normal stiffness & $14 \mathrm{GPa} / \mathrm{m}$ \\
block thickness & $71 \mathrm{~mm}$ & tang. stiffness & $14 \mathrm{GPa} / \mathrm{m}$ \\
block height & $81 \mathrm{~mm}$ & cohesion & $0 \mathrm{MPa}$ \\
& & tensile strength & $0 \mathrm{MPa}$ \\
& & friction angle & $35^{\circ}$ \\
& & dilation angle & $35^{\circ}$
\end{tabular}

In Table 1 we present the numerical parameters that were used in this example. Figure 3 shows the proportionality factor in terms of the number of the considered discretization points. It is observed that the proportionality factor converges to a finite value equal to $\approx 0.4$ 
after using more than 8 contact points. Notice, that the default 2-point-contact discretization of 3DEC [24] provides a much higher collapse load than the numerically exact that it is found with this convergence test. This is owed to the way that $3 \mathrm{DEC}$ calculates the contact forces. In the following sections 8 discretization contact points will be used, as they provide an acceptable balance between accuracy and calculation time (Figure 3 ).

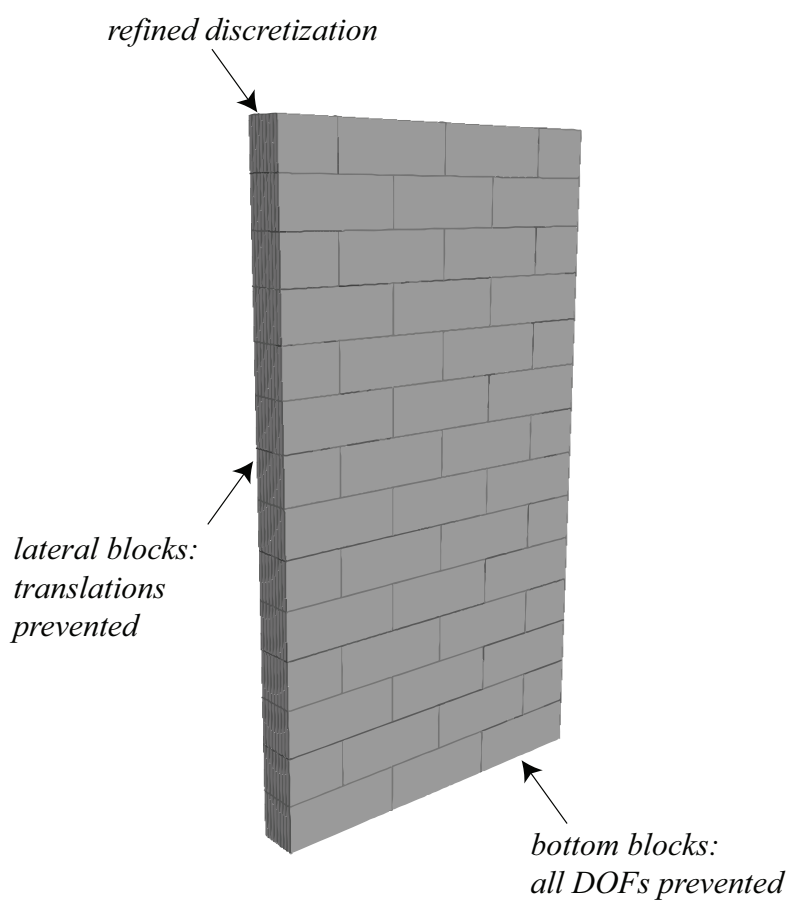

Fig. 2: Boundary conditions for Rondelet's-type test on masonry wallette [44].

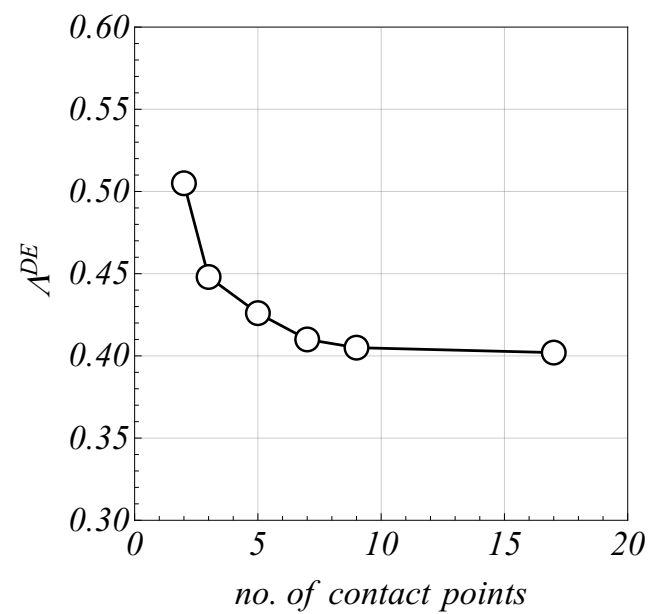

Fig. 3: Variation of the collapse load multiplier $\Lambda$ upon contact discretization across the wall thickness.

\section{Validation of the DEM model based on existing experimental results}

In this section the numerical DEM model is validated by simulating masonry structures for which experimental results are available in the literature. Two experimental configurations that involve out-of-plane behavior are examined in the next two paragraphs: a) halfscale tilting tests carried out at the University of Pavia on dry-stacked stone masonry structures [43] and b) the four-point bending tests made on masonry wallettes at the McMaster University [19].

\subsection{Dry-stacked stone masonry structures}

A series of tests was carried out on dry-stacked stone masonry structures at the University of Pavia [43]. In these tests, 42 masonry specimens made of small marble blocks were tested in quasi-static conditions to tilting. The specimens were supposed to be representative of 1/5-scale dry stone masonry elements, undergoing different out-of-plane failure mechanisms according to those observed in full-scale masonry buildings and analyzed by [13].

No mortar was laid between the block courses and the marble-to-marble friction coefficient was estimated between 0.67 and 0.77 , depending on the applied stress level [43].

The masonry specimens were set on an aluminum base. During the tests, the support was progressively inclined leading the specimens to collapse by tilting. The angle of inclination $\alpha$ was monitored throughout each test. Its value $\alpha_{\mathrm{f}}$ was measured at the onset of each failure mechanism. This gave directly the experimental value of the collapse load multiplier, $\Lambda^{\exp }$ :

$\Lambda^{\exp }=\operatorname{Tan}\left(\alpha_{\mathrm{f}}\right)$.

These experimental tests were numerically reproduced herein in order to validate the numerical model and its assumptions. Only the tests $S 1$ to $S 13$ in [43] were examined (see Figure 7 ). These tests consist in a masonry wall laterally supported by one or two orthogonal walls with different width and aspect ratio [43].

A discrete elements model is built for each specimen by means of 3DEC (see Figure 7). For this purpose, marble blocks are modelled as 80 X 40 X 28 mm rigid blocks. Blocks size is choosen in order to respect the average block dimensions obtained during the sampling phase [43]. In Table 2 we present the numerical values of the joints parameters used in the simulations.

Focusing on minimizing the calculation cost at an acceptable accuracy level, different contact discretizations are used at different parts of the specimens (see 
Table 2: Material properties and geometry for Pavia's tional to the block self-weight $\gamma^{b}$ and are of the form: [43] tests.

\begin{tabular}{llll}
\hline geometry & & joint properties \\
\hline block width & $80 \mathrm{~mm}$ & normal stiffness & $14.0 \mathrm{GPa} /$ \\
block thickness & $28 \mathrm{~mm}$ & tangential stiffness & $14.0 \mathrm{GPa} /$ \\
block height & $40 \mathrm{~mm}$ & cohesion & $0 \mathrm{MPa}$ \\
& & tensile strength & $0 \mathrm{MPa}$ \\
& & friction angle & $33.82^{\circ}$ \\
& & dilation angle & $0^{\circ}$
\end{tabular}

Figure 4). In particular, the part of the wall that undergoes out-of-plane deformations is discretized in refined manner (8 contact points across the wall thickness), while a coarser discretization (2 contact points) is employed for the orthogonal walls which undergo in-plane deformations. Finally, the rigid aluminum support is modeled by a single rigid block, which is fixed (all degrees of freedom prevented). Since the aluminum-tomarble friction coefficient is not provided in [43], the same coefficient with the marble-to-marble contact is used (Table 2).

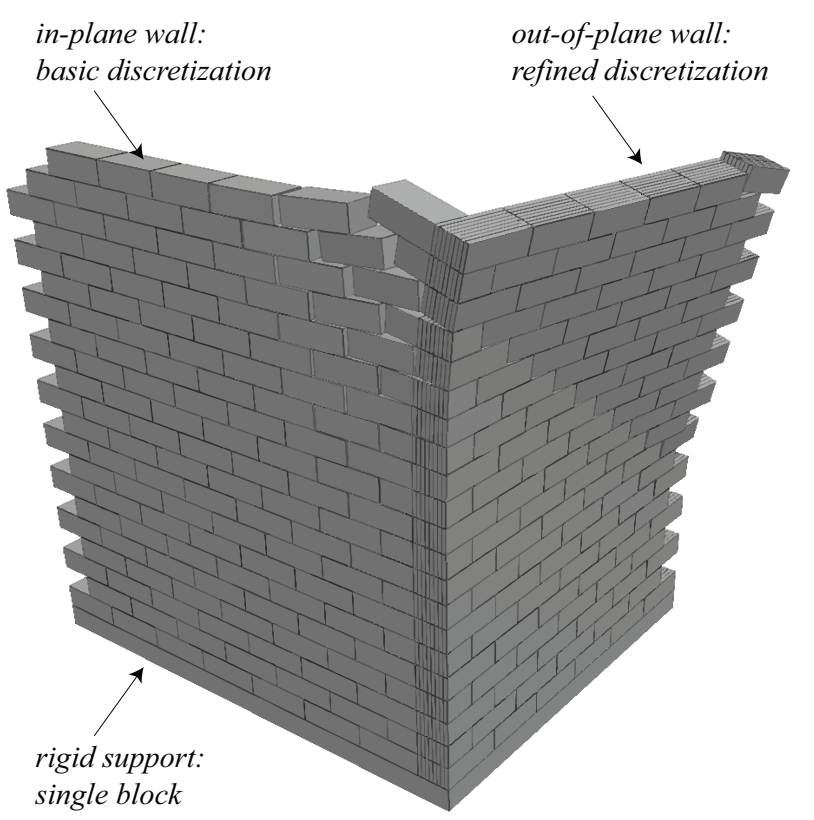

Fig. 4: Different levels of contact discretization used during the simulation of tilting tests carried out at the University of Pavia [43] by means of discrete elements models. Reference to test $S 13$.

During the simulations, horizontal and vertical forces are applied simultaneously to each of the rigid blocks that compose the structure. These forces are propor- $f_{*}^{b}=-\gamma^{b} \operatorname{Cos}(\alpha)$

$f_{\mathrm{h}}^{b}= \pm \gamma^{b} \operatorname{Sin}(\alpha)$.

Starting from the initial configuration $(\alpha=0)$, the angle of inclination is increased slowly during the analyses in order to allow the model to reproduce the exact force distribution exerted during the tilting test. The collapse load multiplier is next computed according to Eq. (5).

The reaction forces $R_{h}$ and $R_{v}$ are extracted from the rigid support of the DEM model and the value for the collapse load multiplier, which is independent of the mass density used in the simulations, is determined. Figure 5 shows the loading path followed by specimen S13 until failure. Failure is defined here at the maximum value of the proportionality factor, which corresponds to local or global sliding and tilting of the masonry specimen. Figure 6 shows the variation of the proportionality factor during the simulation. After the peak an unstable behavior is observed indicating failure (see specimen $S 7$ in Figure 7).

Table 3 gives the relative error committed by the discrete elements model in predicting the collapse load multiplier compared to the experimental results. The error is kept very small, given also the uncertainties regarding the exact material properties and the boundary conditions of the experimental setup. Moreover, the failure patterns between the current DEM model (Figure 7) and the experimental tests ([43]) are in very good agreement. Therefore, we can assert that the current DEM model is representative of the experimental setup.

Table 3: Ultimate load multiplier obtained from Pavia's tilting tests. Comparison between experimental [43] and numerical values from the discrete elements model.

\begin{tabular}{crrr}
\hline specimen & experimental & DEM & \% error \\
\hline$S 1$ & 0.254 & 0.272 & 7.0 \\
$S 2$ & 0.226 & 0.272 & 20.3 \\
$S 3$ & 0.244 & 0.272 & 11.4 \\
$S 5$ & 0.349 & 0.367 & 5.0 \\
$S 6$ & 0.208 & 0.219 & 5.3 \\
$S 7$ & 0.291 & 0.312 & 7.0 \\
$S 8$ & 0.362 & 0.357 & -1.4 \\
$S 9$ & 0.352 & 0.357 & 1.4 \\
$S 10$ & 0.213 & 0.238 & 11.7 \\
$S 11$ & 0.097 & 0.118 & 21.6 \\
$S 12$ & 0.129 & 0.152 & 17.8 \\
$S 13$ & 0.181 & 0.203 & 11.9 \\
\hline
\end{tabular}




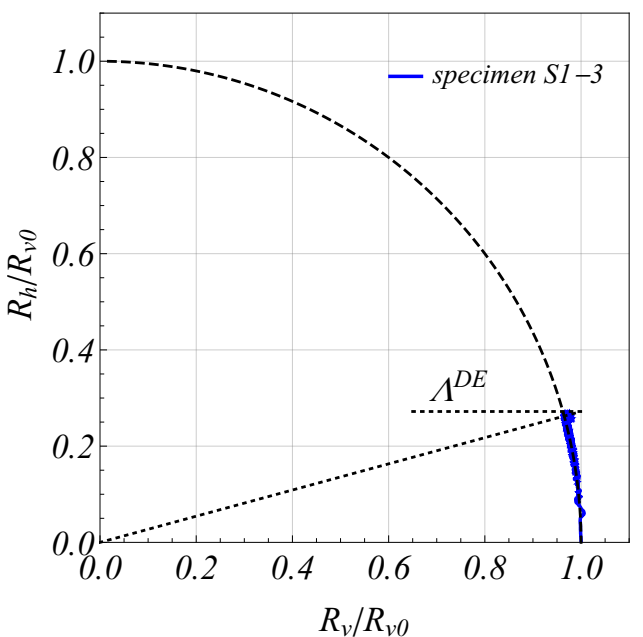

Fig. 5: $R_{\mathrm{v} 0}$ is the self weight of the structure. Loading path followed by the DEM model (blue solid line), loading path imposed by the test (dashed line), lambda value extracted (dotted line).

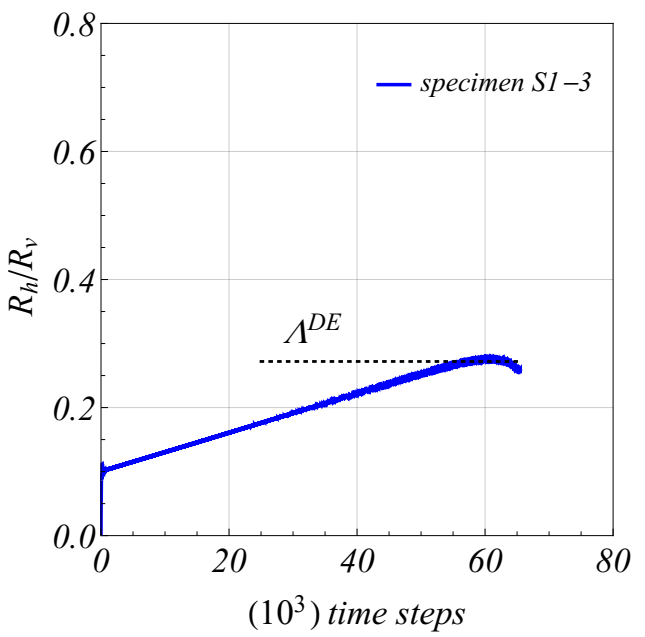

Fig. 6: Ratio between horizontal and vertical reaction force versus number of time steps performed by 3DEC until reaching specimen failure.

\subsection{Four-point tests of masonry wallettes}

A series of four-point bending tests was performed on block masonry wallettes at the University of McMaster [19]. In this testing program, 25 masonry wallettes were tested under monotonic bending until failure. The wallettes were laid with joints having different orientations with respect to the bending direction (see Figure 8). In this way, the flexural tensile strength of the masonry was tested for different material orientations. The wallettes were built using large double-cell hollow concrete blocks. Both the head and the bed joints were filled with mortar layers of approximately $10 \mathrm{~mm}$ thick- ness. The masonry wallettes had regular shape, with dimensions that were chosen to provide samples that were large enough to be representative of an entire masonry wall [19]. Their width was $790 \mathrm{~mm}$ and was kept constant throughout the testing program. Their length in the longitudinal (bending) direction was of approximately $1600 \mathrm{~mm}$. This length was slightly varied during the experimental tests depending on the joints orientation, in order to be sufficiently large to accommodate all possible failure mechanisms in the region of constant moment [19].

The specimens were laid on a pin-and-roller set of supports at their ends and the load was applied at two intermediate points of the specimens and it was uniformly distributed along the width through beams pinned directly to their surface (see Figure 8). The load was controlled by means of a hydraulic jack and a load cell, and progressively increased up to wallettes failure. The failure load was recorded for each material orientation and the failure pattern was observed [19].

Five configurations related to different bed joints orientations were tested, namely $\Theta=0^{\circ}, 15^{\circ}, 45^{\circ}, 75^{\circ}$ and $90^{\circ}$. All specimens with orientation between $0^{\circ}$ and $45^{\circ}$ failed with an apparent stepped or toothed crack pattern along a combination of bed and head joints. Only marginal blocks fracture was observed in the case of $\Theta=0^{\circ}$. Similarly, a failure mechanism consisting of bed joint debonding was observed for specimens with $\Theta=75^{\circ}$ and $90^{\circ}$ [19].

A discrete elements model capable of reproducing the aforementioned experiments was built for each configuration. The blocks size, the joints orientation, the boundary conditions and the same loading protocol were reproduced numerically herein in order to validate the DEM approach. It is worth mentioning that the quality of these experimental results was quite satisfactory in order to be used also by other researchers for numerical simulations (see $[29,35,7]$ ).

Figure 8 shows a cross-section of the discrete elements model adopted. Concrete blocks are modelled as discrete elements with effective size 400 X 200 X 150 $\mathrm{mm}$. Details about the actual length of the specimens are absent from [19]. Therefore, the masonry wallettes have fixed dimensions of 790 X $1600 \mathrm{~mm}$. According to the modeling strategy exposed in the previous section, the wallettes are discretized in a refined manner $(8$ contact points at the joints). The boundary conditions were modeled with two pairs of blocks as shown in Figure 8. The first pair of blocks is fixed, while a vertical constant velocity is applied to the second pair. Simulations are stopped once the specimen has failed. This corresponds to a sudden drop in the vertical reaction force, measured by 3DEC, and it is accompanied by 


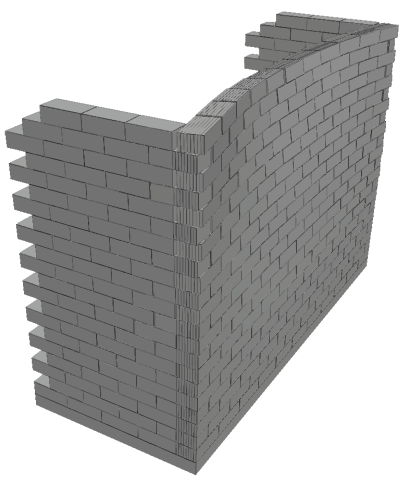

$S 1-3$

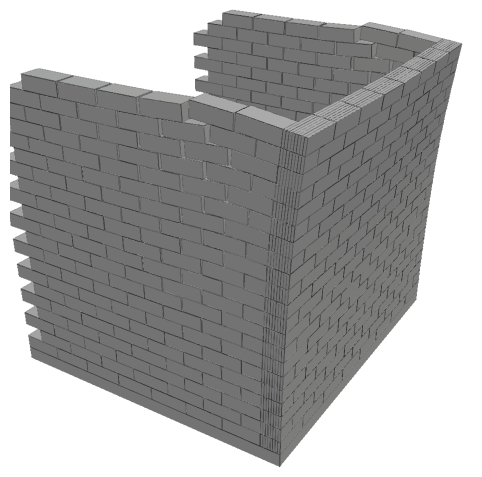

$S 7$

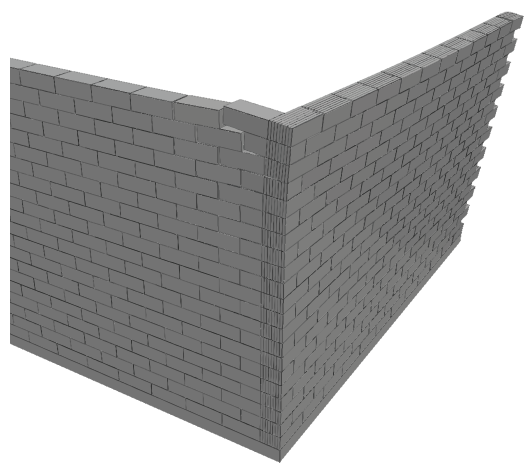

$S 11$

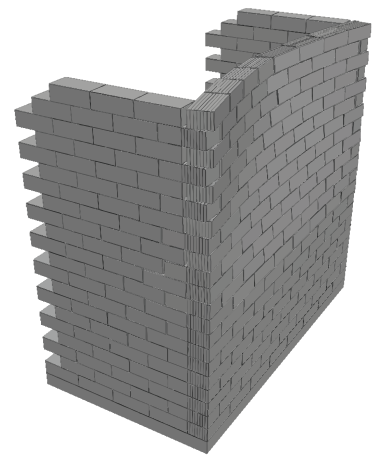

$S 5$

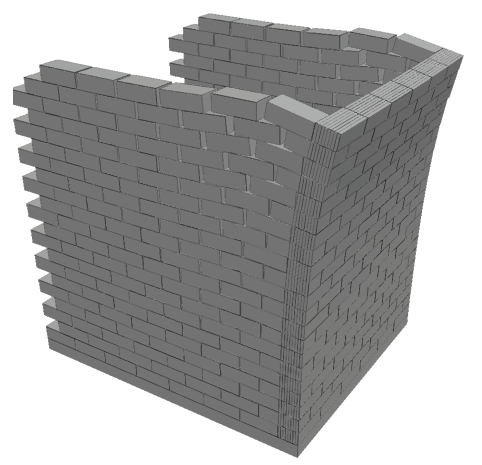

$S 8-9$

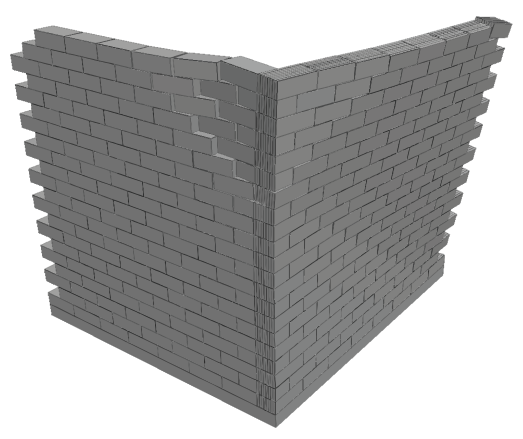

$S 12$

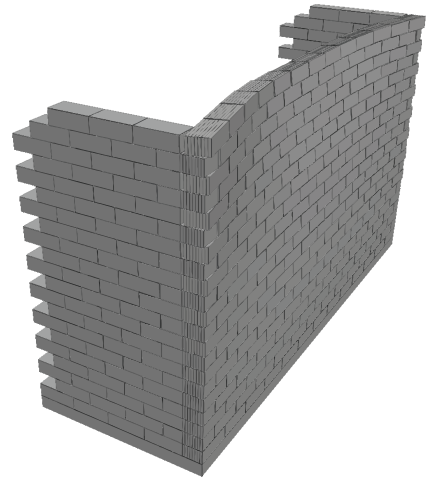

$S 6$

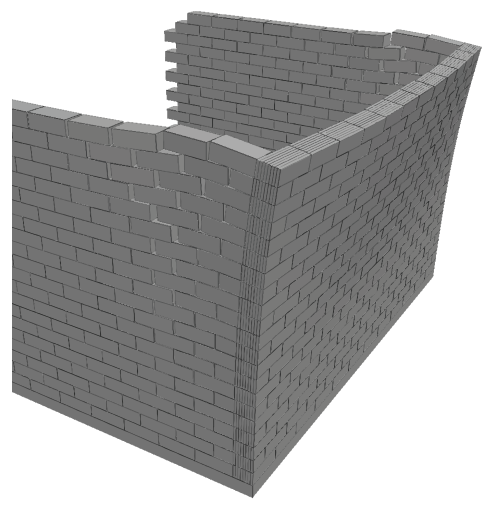

$S 10$

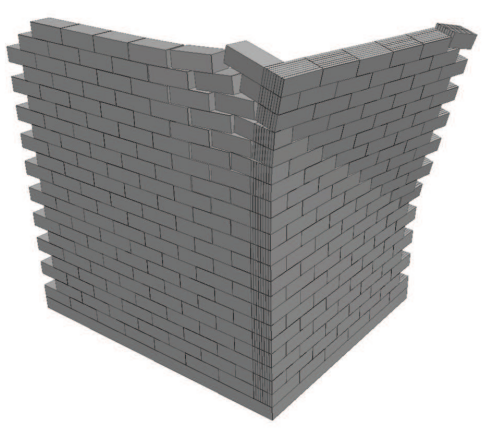

$S 13$

Fig. 7: Discrete elements models of the stone masonry structures tested to tilting at the University of Pavia [43]. Deformed configurations at failure.

an increase of the kinetic energy. The flexural tensile strength is related to the maximum bending moment
$M_{\max }$ by the expression:

$f_{x t}=\frac{6 M_{\max }}{b t^{2}}$,

where $b$ is the width of the specimen and $t$ its thickness. 


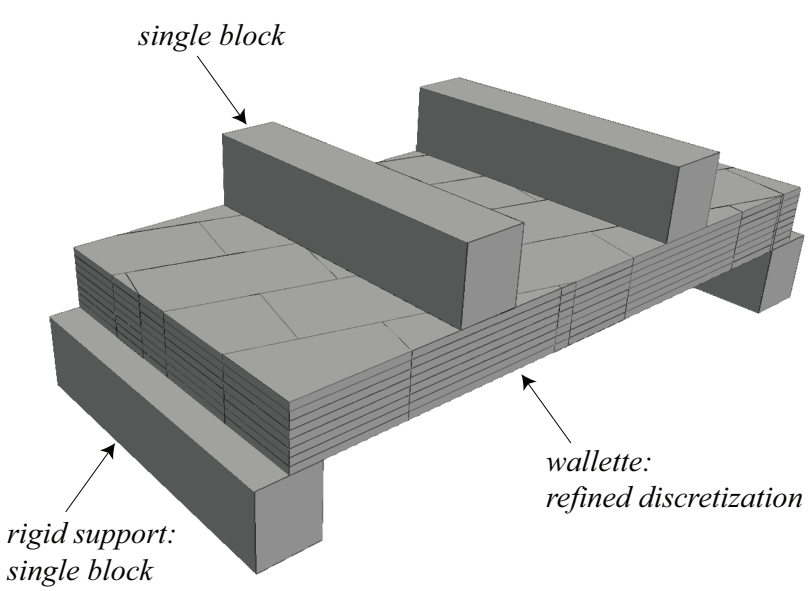

Fig. 8: Cross-section of the discrete elements model adopted for the simulation of the four-point bending tests carried out on masonry wallettes at the University of McMaster [19]. Reference to the configuration with bed joints orientation of $15^{\circ}$.

Table 4: Material properties and geometry for Gazzola's [19] tests.

\begin{tabular}{llll}
\hline geometry & \multicolumn{3}{c}{ joint properties } \\
\hline block width & $400 \mathrm{~mm}$ & normal stiffness & $7 \mathrm{GPa} / \mathrm{m}$ \\
block thickness & $150 \mathrm{~mm}$ & tangential stiffness & $7 \mathrm{GPa} / \mathrm{m}$ \\
block height & $200 \mathrm{~mm}$ & cohesion & $0.54 \mathrm{MPa}$ \\
& & tensile strength & $0.36 \mathrm{MPa}$ \\
& & friction angle & $36^{\circ}$ \\
& & dilation angle & $0^{\circ}$
\end{tabular}

The material properties used for the DEM analyses are presented in Table 4 . It is worth mentioning that not a lot of details were given in [19] about the material properties, except for the uniaxial compressive strength of the mortar and the blocks. This latter is relatively high compared to the values of the flexural tensile strength obtained from the tests. This, together with the observed failure patterns, justifies the softcontact/rigid blocks assumption mentioned in Section 2 and used throughout this paper.

In Figure 9 we juxtapose the values of the flexural tensile strength obtained by the DEM model with the experimental data. The mean value and the standard deviation of these latter are plotted, together with the best fit trend found by [19], which takes the form:

$f_{x t}(\Theta)=f_{t n} \operatorname{Sin}^{2}[\Theta]+f_{t p} \operatorname{Cos}^{2}[\Theta]$,

where $f_{t n}$ and $f_{t p}$ is the tensile strength measured in the direction normal and parallel to the bed joints orientation, respectively. The DEM model provides a good agreement with the experimental results for the various joints orientations. This is also confirmed qualita- tively by comparing the failure mechanisms between the present numerical model and the experimental results (see Figure 10 and $[19,18]$ ).

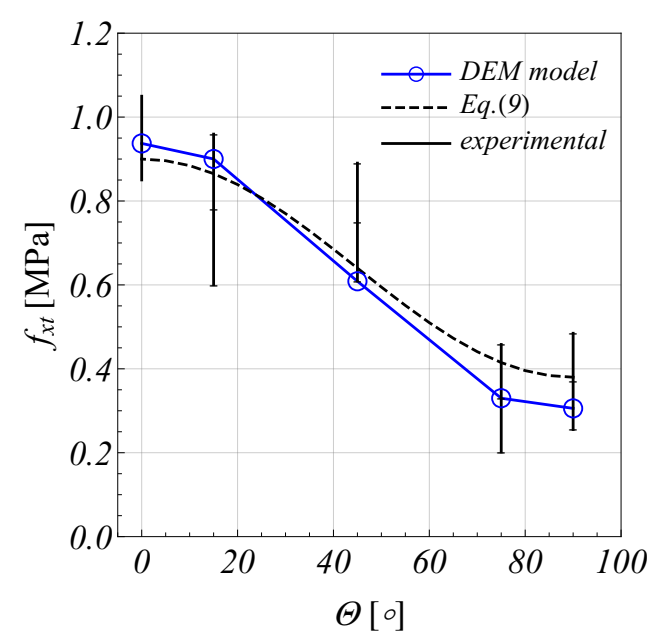

Fig. 9: Flexural tensile strength of masonry for different bed joints orientation. Comparison between experimental [19] and numerical values given by the discrete elements model.

In the previous section, the numerical results from the DEM model were compared to out-of-plane tests of masonry wallettes and structures. The agreement between the numerical and experimental results was very good, not only as far it concerns the ultimate failure load, but also the failure mode. Therefore, one could assert that the DEM model could provide not only qualitative, but also quantitative results as far it concerns the out-ofplane behavior of masonry and its dependence on the dilatancy of joints and the size of the building blocks.

\subsection{Joints dilatancy effect}

The effect of the dilatancy of the joints is illustrated by comparing the strength of the masonry configurations presented in the above sections for dilatant joints (associative case, $\Psi=\Phi$ ) and non-dilatant joints (nonassociative case, $\Psi=0)$.

In Figure 11, we present the collapse load multiplier $\Lambda^{D E}$ in function of the contact discretization fineness for zero-dilatancy joints (see Section 2.2). As in the case of dilatant joints, convergence is observed for eight and more contact points per block face. As expected, the ultimate failure load is lower in the non-associate case, 


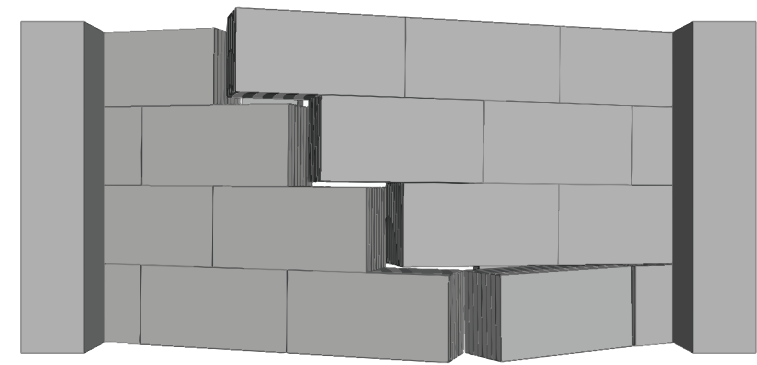

$\Theta=0^{\circ}$

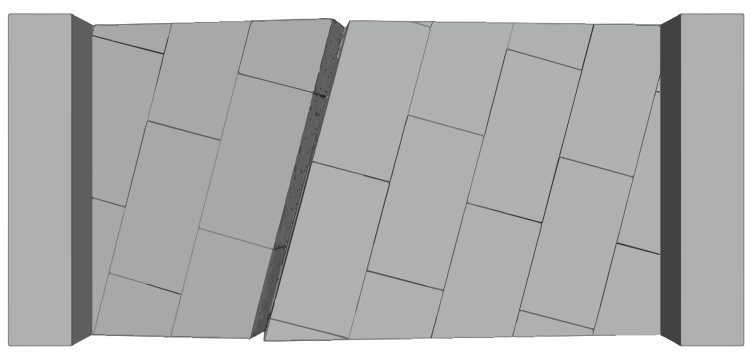

$$
\Theta=75^{\circ}
$$

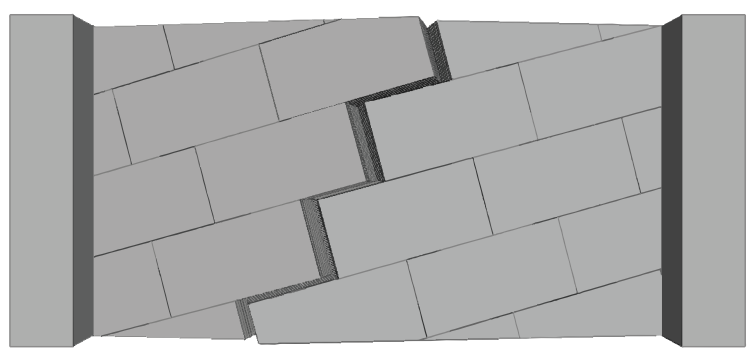

$\Theta=15^{\circ}$

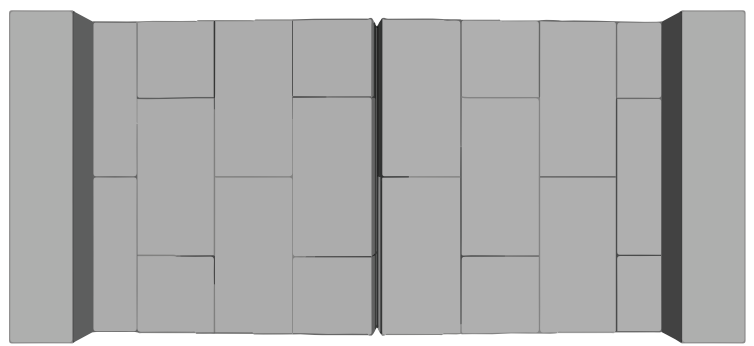

$\Theta=90^{\circ}$

Fig. 10: Different failure mechanisms developed in the discrete elements models used for simulating the fourbending tests on block masonry wallettes [19]. Stepped failure pattern $\left(\Theta=0^{\circ}, 15^{\circ}\right)$ and bed joints debonding $\left(\Theta=75^{\circ}, 90^{\circ}\right)$.

even though the vertical loading is low (self-weight, no confinement). More specifically, the relative difference between the two cases is of the order of $25 \%$ (see Figure 12). As shown qualitatively in Figure 13, due to dilatancy masonry joints have the tendency to increase the inter-block distance during bending and shearing.

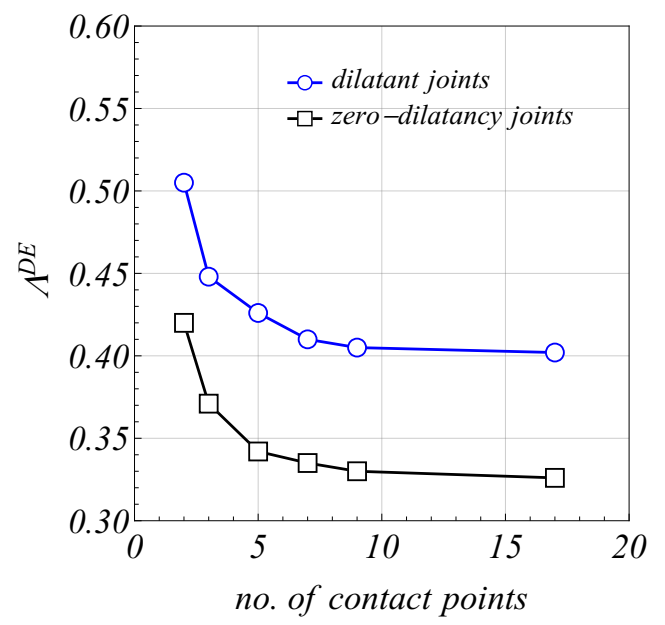

Fig. 11: Rondelet's test. Variation of the collapse load multiplier $\Lambda^{D E}$ upon contact discretization across the wall thickness. Comparison between dilatant joints and joints with zero dilatancy angle.

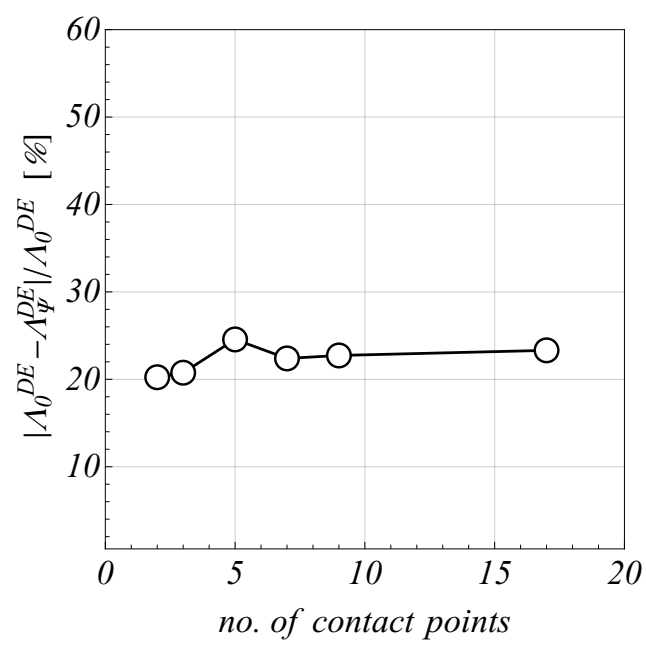

Fig. 12: Rondelet's test. Ratio between collapse load multiplier for non-dilatant $\Lambda_{0}^{D E}$ and dilatant joints $\Lambda_{\Psi}^{D E}$.

A similar effect of the dilatancy on the overall strength of masonry is also observed in the case of the Pavia's tests (see Section 3.1). In Figure 14 we present the collapse load multiplier for each one of the tests presented in Section 3.1 (see also Table 3) and in Table 5 we summarize the numerical results. Considering dilatant joints leads to important discrepancies between the nu- 


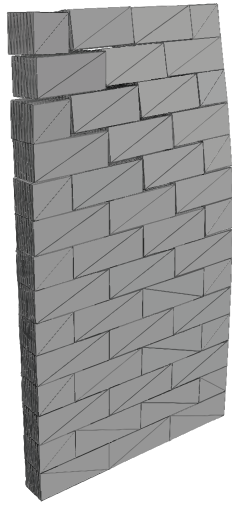

Dilatant joints $(\Psi=\Phi)$

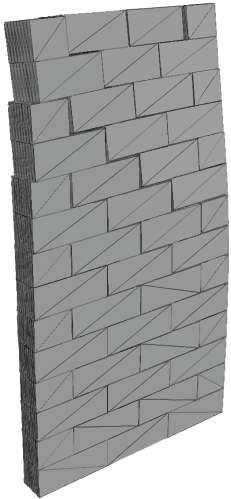

Joints with zerodilatancy $(\Psi=0)$
Fig. 13: Deformed configuration at failure of Rondolet's type test with dilatant and non-dilatant joitns.

merical and the experimental results regarding the ultimate load (see Figure 15). Moreover, dilatant joints (associative case) leads to non-conservative predictions for the out-of-plane strength of the masonry, even under low confinement.

Associative plastic flow rules are usually chosen in limit analysis of masonry (e.g. $[12,34,36,50])$. Therefore, these approaches can overestimate the masonry strength if the parameters are based on the the experimentally derived angle of friction and no adequate safety factors are used. This overestimation of the critical load can be even more significant for confined or reinforced masonry or for masonry under heavy vertical loading. Finally, under cyclic excitation, the presence of non-dilatant joints can reduce the energy dissipation of the structure and lead to inappropriate estimations regarding the dynamic behavior of the structure.

\subsection{Building blocks size effect}

The size of the building blocks can influence the compression and the shear strength of the structure as well as its stiffness (see [41] for a comprehensive review). Various reasons for this effect that herein we call scale effect for simplicity, can be identified. For instance, the strength of the masonry units, which is scale-dependent (see [25]), the thickness of the interfaces (for mortared masonry) and most important the number of the joints in the structure can have a direct effect in the overall strength.

Here we perform numerical tests to highlight the scale effect for the Pavia tests (Section 3.1) and for the

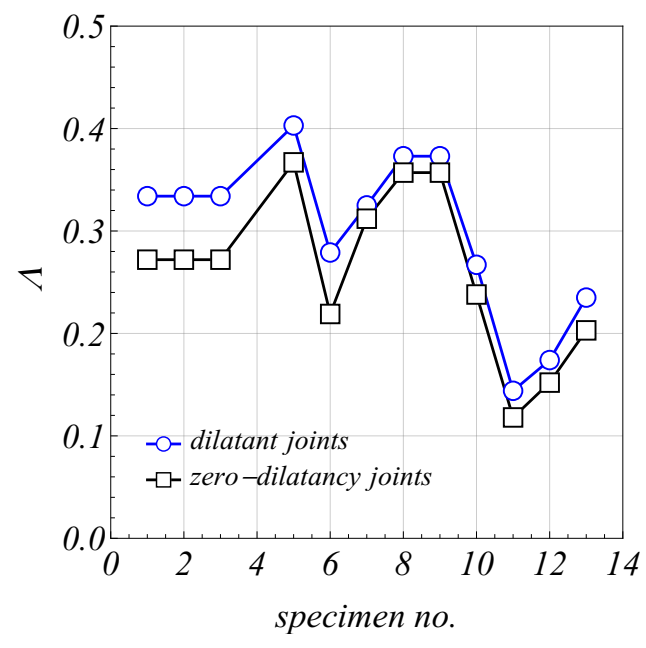

Fig. 14: Pavia's tests. Variation of the collapse load multiplier $\Lambda^{D E}$ upon contact discretization across the wall thickness. Comparison between dilatant joints and joints with zero dilatancy angle.

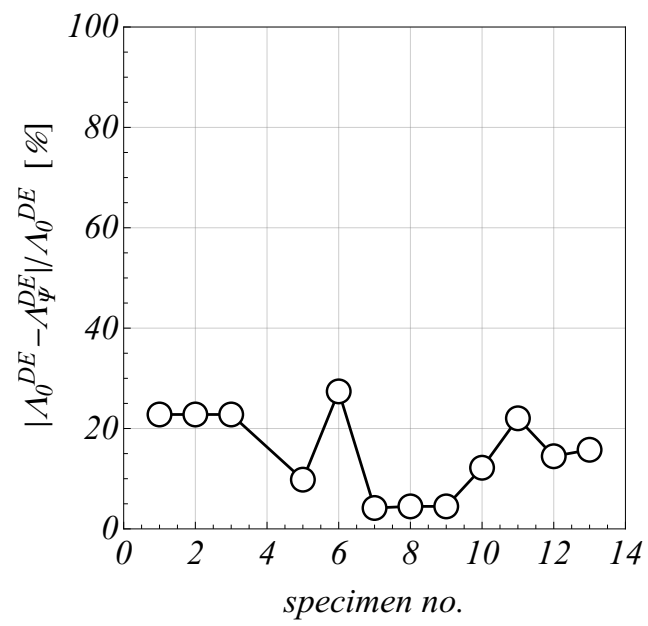

Fig. 15: Pavia's tests. Ratio between collapse load multiplier measure for non dilatant $\Lambda_{0}^{D E}$ and dilatant joints $\Lambda_{\Psi}^{D E}$.

McMaster tests (Section 3.2). In the former series of tests, all the specimens were re-tested by using blocks that are half and twice their original size. In Figure 16 and 17 we present the difference of the maximum proportionality factor, $\Lambda^{D E}$, for the various block sizes. It can be observed that the larger the blocks are, the higher the strength of the masonry wall becomes. The mechanical properties shown in Table 2 were used in these simulations.

Finally, in Figure 18 and 19 we present, respectively, the influence of the size of the blocks on the apparent flexural tensile strength $f_{x t}$ (Eq.(8)) and on the apparent maximum bending moment for the Gazzola's et al. 
Table 5: Ultimate load multiplier obtained from Pavia's tilting tests. Comparison between dilatant and non-dilatant joints. The columns error indicate the relative error between the numerical and the experimental results as they are presented in Table 3.

\begin{tabular}{|c|c|c|c|c|c|c|}
\hline \multirow[b]{2}{*}{ specimen } & \multirow[b]{2}{*}{ exp. } & \multicolumn{2}{|c|}{ zero-dilatancy joints } & \multicolumn{2}{|c|}{ dilatant joints } & \multirow{2}{*}{$\begin{array}{r}\text { comparison } \\
\text { ratio }\end{array}$} \\
\hline & & DEM & $\%$ error & DEM & $\%$ error & \\
\hline$S 1$ & 0.254 & 0.272 & 7.0 & 0.334 & 31.5 & 0.81 \\
\hline$S 2$ & 0.226 & 0.272 & 20.3 & 0.334 & 47.8 & 0.81 \\
\hline$S 3$ & 0.244 & 0.272 & 11.4 & 0.334 & 36.9 & 0.81 \\
\hline$S 5$ & 0.349 & 0.367 & 5.0 & 0.403 & 15.5 & 0.91 \\
\hline$S 6$ & 0.208 & 0.219 & 5.3 & 0.279 & 34.1 & 0.78 \\
\hline$S 7$ & 0.291 & 0.312 & 7.0 & 0.325 & 11.7 & 0.96 \\
\hline$S 8$ & 0.362 & 0.357 & -1.4 & 0.373 & 3.0 & 0.96 \\
\hline$S 9$ & 0.352 & 0.357 & 1.4 & 0.373 & 6.0 & 0.96 \\
\hline$S 10$ & 0.213 & 0.238 & 11.7 & 0.267 & 25.4 & 0.89 \\
\hline$S 11$ & 0.097 & 0.118 & 21.6 & 0.144 & 48.5 & 0.82 \\
\hline$S 12$ & 0.129 & 0.152 & 17.8 & 0.174 & 34.5 & 0.88 \\
\hline$S 13$ & 0.181 & 0.203 & 11.9 & 0.235 & 29.8 & 0.86 \\
\hline
\end{tabular}

tests [19]. The material properties in Table 4 were used for the simulations and all the dimensions of the blocks were scaled. Again, the larger the blocks are the higher the strength of the masonry is.

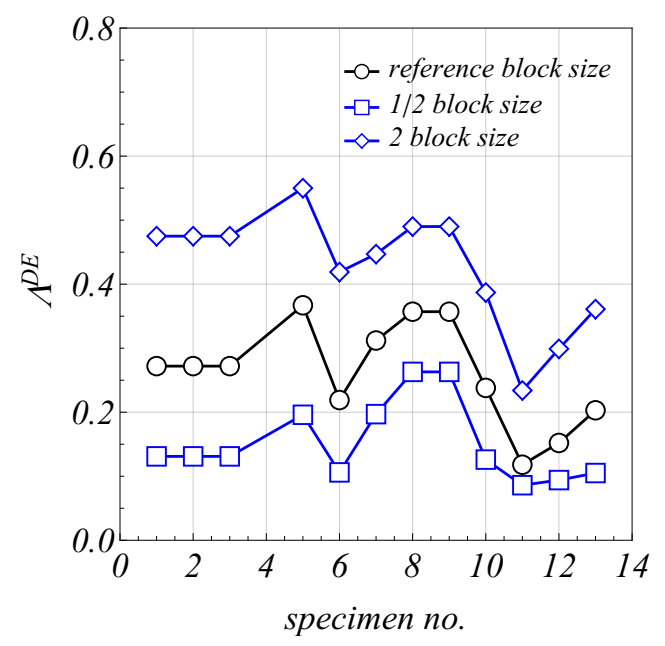

Fig. 16: Pavia's tests. Variation of the collapse load multiplier $\Lambda^{D E}$ for various block sizes.

\section{Conclusions}

Masonry is a composite material, whose mechanical behavior and strength is influenced by many factors. Here we examined and quantified two of them, i.e. the dilatancy of the joints and the size of the building blocks. For this purpose, a numerical model based on the DEM was presented and its results were compared to well documented and characteristic laboratory tests of ma-

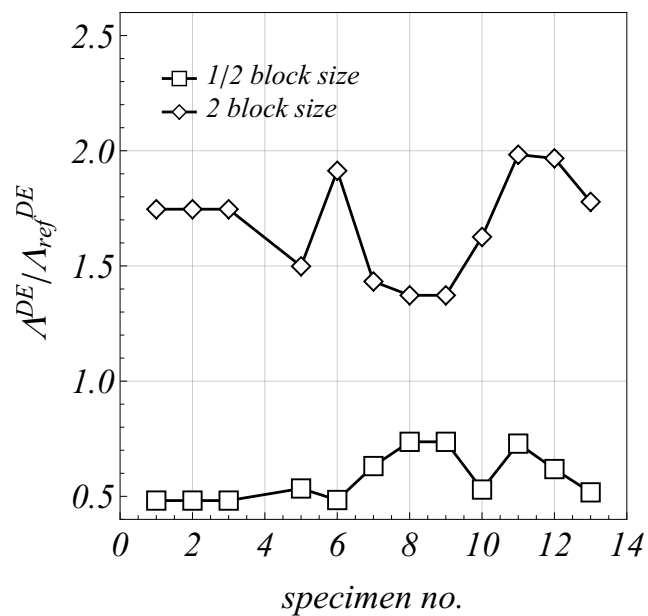

Fig. 17: Pavia's tests. Ratio of the collapse load multiplier for various block sizes $\Lambda^{D E}$ over the collapse load multiplier for the reference block size $\Lambda_{r e f}^{D E}$.

sonry walettes and structures. A very good agreement was found between the numerical results and the experimental ones. When possible, the micromechanical parameters used for the model (geometry and material properties) were selected according to the experimentally measured ones. In the absence of exact values in some tests, typical average values were considered. In this paper, we focused mainly on the out-of-plane behavior of masonry, which emphasized combined torsion, flexural and shear deformations at the level of the masonry joints.

Once the numerical model was validated by comparison to the experimental tests, it was used to assess in a controlled manner the influence of the joints dilatancy and of the size of the blocks to the overall strength of the system. For the numerical examples that were inves- 


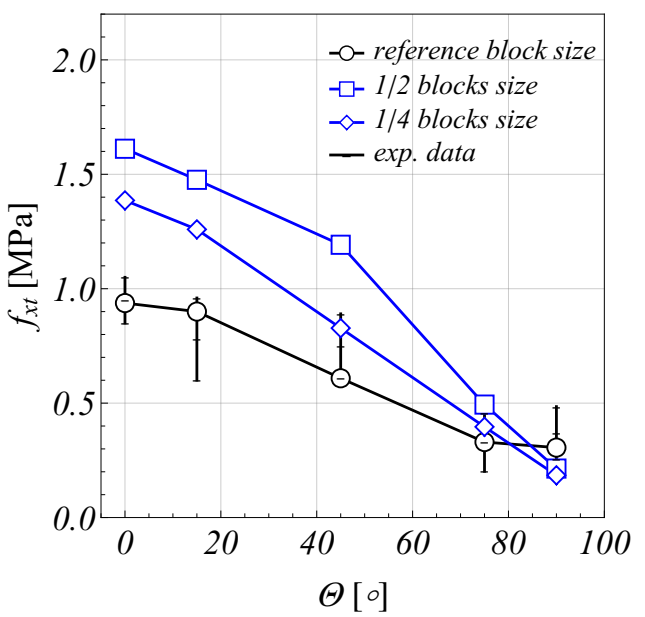

Fig. 18: McMaster's tests. Influence of the size of the blocks on the apparent flexural tensile strength $f_{x t}$.

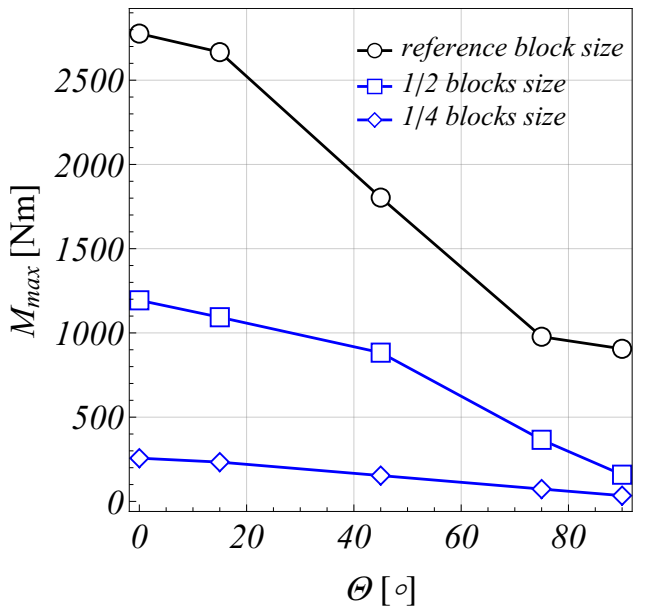

Fig. 19: McMaster's tests. Influence of the size of the blocks on the apparent maximum bending moment.

tigated, it was shown that joints showing zero dilatancy reduce considerably (about 25\%) the stress of masonry. This is not an unexpected result (see Radenkovic theorem [45] and $[4,37,38]$ for applications to discrete block assemblages, among others), but here it was quantified through simple examples showing its important impact. From the modeling point of view, the upper or lower bounds provided by limit analysis can be far from the exact failure of masonry, because their derivation is based on the associativity of the underlying system. For the configuration considered (tilting test), the upper bound theorem can lead to non-conservative estimations of the order of $30 \%$ depending the geometry and the type of loading. These effects were significant even under low confinement, and it is expected to be more important under high compressive and/or cyclic loads (lower floors of buildings, confined masonry, reinforced masonry etc.).

As far it concerns the effect of the size of the blocks, which was called here scale effect, it was found that the larger the blocks are, the higher the strength of the masonry becomes. In other words the bulgier the blocks, the better it is, at least for the examples examined herein. This is analog to the scale effect studied by [23] for rocking.

The results obtained in this paper can be useful for improving our understanding on the behavior of masonry structures under out-of-plane and combined inplane/out-of-plane deformations. Moreover, from the modeling point of view, they can be important in applications of modeling large masonry structures (retaining walls, walls, buildings etc.) with numerical methods based on continuum mechanics (upscaling/homogenization). These approaches should be able to take into account the non-associative character of the masonry material and its intrinsic internal lengths. The use of higher order continuum theories (e.g. $[20,51,46,1,52,14,3,54,5]$ ) is a natural theoretical framework for this purpose.

Acknowledgements The authors would like to acknowledge the valuable help of Dr Jose Lemos for the technical support he provided in using 3DEC.

Conflict of Interest

The authors declare that they have no conflict of interest.

\section{References}

1. Addessi, D., Sacco, E., Paolone, A.: Cosserat model for periodic masonry deduced by nonlinear homogenization. European Journal of Mechanics - A/Solids 29(4), 724-737 (2010). DOI 10.1016/j.euromechsol.2010.03.001. URL http://linkinghub.elsevier.com/retrieve/pii/ S0997753810000410

2. Azevedo, J., Sincraian, G., Lemos, J.V.: Seismic behavior of blocky masonry structures (2000). DOI 10.1193/1. 1586116

3. Bacigalupo, A., Gambarotta, L.: Computational twoscale homogenization of periodic masonry: Characteristic lengths and dispersive waves. Computer Methods in Applied Mechanics and Engineering 213216, 16-28 (2012). DOI 10.1016/j.cma.2011.11.020. URL http://linkinghub.elsevier.com/retrieve/pii/ S0045782511003665

4. Baggio, C., Trovalusci, P.: Limit Analysis for NoTension and Frictional Three-Dimensional Discrete Systems. Mechanics of Structures and Machines 26(3), 287-304 (1998). DOI 10.1080/08905459708945496. URL http://www.tandfonline.com/doi/abs/10.1080/ 08905459708945496

5. Baraldi, D., Cecchi, A., Tralli, A.: Continuous and discrete models for masonry like material: A critical comparative study. European Journal of Mechanics, A/Solids 50, 39-58 (2015). DOI 10.1016/j.euromechsol.2014.10. 007. URL http://dx.doi.org/10.1016/j.euromechsol. 2014.10.007 
6. Besdo, D.: Inelastic behavior of plane frictionless blocksystems described as cosserat media. Archives of Mechanics 37(6), 603-619 (1985)

7. Bui, T.T., Limam, A.: Masonry Walls under Membrane or Bending Loading Cases : Experiments and Discrete Element Analysis. In: Proceedings of the Eleventh International Conference on Computational Structures Technology (2012)

8. Çakt, E., Saygl, Ö., Lemos, J.V., Oliveira, C.S.: Discrete element modeling of a scaled masonry structure and its validation. Engineering Structures 126, 224-236 (2016). DOI 10.1016/j.engstruct.2016.07.044. URL http://linkinghub.elsevier.com/retrieve/pii/ S0141029616303807

9. Cecchi, A., Milani, G., Tralli, A.: Validation of Analytical Multiparameter Homogenization Models for Out-ofPlane Loaded Masonry Walls by Means of the Finite Element Method 131(February), 185-198 (2005)

10. Cecchi, A., Milani, G., Tralli, A.: A ReissnerMindlin limit analysis model for out-of-plane loaded running bond masonry walls. International Journal of Solids and Structures 44(5), 1438-1460 (2007). DOI 10.1016/j.ijsolstr. 2006.06.033. URL http://linkinghub.elsevier.com/ retrieve/pii/S0020768306002423

11. Cecchi, A., Sab, K.: A comparison between a 3D discrete model and two homogenised plate models for periodic elastic brickwork. International Journal of Solids and Structures 41(9-10), 2259-2276 (2004). DOI 10. 1016/j.ijsolstr.2003.12.020. URL http://linkinghub. elsevier.com/retrieve/pii/S0020768303007224

12. Colas, A.S., Morel, J.C., Garnier, D.: Yield design of drystone masonry retaining structures-Comparisons with analytical, numerical, and experimental data. International Journal for Numerical and Analytical Methods in Geomechanics 32(14), 1817-1832 (2008). DOI 10.1002/nag.697. URL http://doi.wiley.com/10.1002/nag.697

13. D'Ayala, D., Speranza, E.: Definition of Collapse Mechanisms and Seismic Vulnerability of Historic Masonry Buildings. Earthquake Spectra 19(3), 479-509 (2003). DOI 10.1193/1.1599896

14. de Bellis, M., Addessi, D.: A cosserat based multi-scale model for masonry structures. International Journal for Multiscale Computational Engineering 9(5), 543-563 (2011)

15. DeJong, M.J., Vibert, C.: Seismic response of stone masonry spires: Computational and experimental modeling. Engineering Structures 40, 566-574 (2012). DOI 10. 1016/j.engstruct.2012.03.001. URL http://linkinghub. elsevier.com/retrieve/pii/S0141029612001186

16. Dimitrakopoulos, E.G., DeJong, M.J.: Revisiting the rocking block: closed-form solutions and similarity laws. Proceedings of the Royal Society A: Mathematical, Physical and Engineering Sciences 468(2144), 2294-2318 (2012). DOI 10.1098/rspa.2012.0026. URL http://rspa.royalsocietypublishing.org/cgi/doi/ 10.1098/rspa.2012.0026

17. Dimitri, R., De Lorenzis, L., Zavarise, G.: Numerical study on the dynamic behavior of masonry columns and arches on buttresses with the discrete element method. Engineering Structures 33(12), 3172-3188 (2011). DOI 10.1016/j.engstruct.2011.08.018. URL http://dx.doi. $\mathrm{org} / 10.1016 / \mathrm{j}$.engstruct. 2011.08.018

18. Gazzola, E., Drysdale, R.: A Component Failure Criterion for Blockwork in Flexure. In: Structures Congress. New Orleans, Louisiana (1986)

19. Gazzola, E., Drysdale, R.R.G., Essawy, A.A.: Bending of concrete masonry walls at different angles to the bed joints. In: Third North American Masonry Conference. Arlington, Texas (1985)

20. Germain, P.: The Method of Virtual Power in Continuum Mechanics. Part 2: Microstructure. SIAM Journal on Applied Mathematics 25(3), 556-575 (1973). DOI 10.1137/0125053. URL http://epubs.siam.org/doi/ abs/10.1137/0125053

21. Godio, M., Stefanou, I., Sab, K., Sulem, J.: Cosserat Elastoplastic Finite Elements for Masonry Structures. Key Engineering Materials 624, 131-138 (2014). DOI 10.4028/www.scientific.net/KEM.624.131. URL http: //www.scientific.net/KEM.624.131

22. Godio, M., Stefanou, I., Sab, K., Sulem, J.: Dynamic finite element formulation for Cosserat elastic plates. International Journal for Numerical Methods in Engineering 101(13), 992-1018 (2015). DOI 10.1002/nme.4833. URL http://doi.wiley.com/10.1002/nme.4833

23. Housner, G.: The behavior of inverted pendulum structures during earthquakes. Bulletin of the Seismological Society of America 53(2), 403-417 (1963)

24. Itasca Consulting Group: 3DEC 5.0 (2013)

25. Kourkoulis, S.K., Ganniari-Papageorgiou, E.: Experimental study of the size- and shape-effects of natural building stones. Construction and Building Materials 24(5), 803-810 (2010). DOI 10.1016/j.conbuildmat. 2009.10.027. URL http://linkinghub.elsevier.com/ retrieve/pii/S095006180900364X

26. Lemos, J.V.: Discrete Element Modeling of Masonry Structures. International Journal of Architectural Heritage 1(2), 190-213 (2007). DOI 10.1080/ 15583050601176868. URL http://www.tandfonline. com/doi/abs/10.1080/15583050601176868

27. Lemos, J.V.: Numerical issues in the representation of masonry structural dynamics with discrete elements. Compdyn (June), 13-16 (2007). URL http://scholar.google.com/scholar?hl=en $\{\&\} b t n G=$ Search $\{\&\}$ q=intitle $:$ NUMERICAL+ISSUES+IN+THE+ REPRESENTATION+OF+MASONRY+structural+dynamics+ with + discrete+elements $\{\#\} 2$

28. Lengyel, G., Bagi, K.: Numerical analysis of the mechanical role of the ribs in groin vaults. Computers \& Structures 158, 42-60 (2015). DOI 10.1016/j.compstruc. 2015.05.032. URL http://linkinghub.elsevier.com/ retrieve/pii/S0045794915001789

29. Lourenço, P.B.: Anisotropic softening model for masonry plates and shells. Journal of structural engineering 126(9), 1008-1016 (2000)

30. Lourenço, P.B., Ramos, L.S.F.: Characterization of Cyclic Behavior of Dry Masonry Joints. Journal of Structural Engineering 130(5), 779-786 (2004). DOI 10.1061/(ASCE)0733-9445(2004)130:5(779)

31. Makris, N., Konstantinidis, D.: The rocking spectrum and the limitations of practical design methodologies. Earthquake Engineering \& Structural Dynamics 32(2), 265-289 (2003). DOI 10.1002/eqe.223. URL http: //doi.wiley.com/10.1002/eqe.223

32. Makris, N., Vassiliou, M.F.: Planar rocking response and stability analysis of an array of free-standing columns capped with a freely supported rigid beam. Earthquake Engineering \& Structural Dynamics 42(3), 431449 (2013). DOI 10.1002/eqe.2222. URL http://doi. wiley.com/10.1002/eqe. 2222

33. Masiani, R., Rizzi, N., Trovalusci, P.: Masonry as structured continuum. Meccanica 30(6), 673-683 (1995). DOI 10.1007/BF00986573. URL http://www.springerlink. com/index/10.1007/BF00986573 
34. Milani, G.: Homogenized limit analysis of FRP-reinforced masonry walls out-of-plane loaded. Computational Mechanics 43(5), 617-639 (2009). DOI 10.1007/ s00466-008-0334-7

35. Milani, G., Lourenço, P.B., Tralli, A.: Homogenization Approach for the Limit Analysis of Out-of-Plane Loaded Masonry Walls. Journal of Structural Engineering 132(October), 1650-1663 (2006). DOI 10.1061/ (ASCE)0733-9445(2006)132:10(1650)

36. Milani, G., Lourenço, P.B., Tralli, A.: Homogenized rigidplastic model for masonry walls subjected to impact. International Journal of Solids and Structures 46(2223), 4133-4149 (2009). DOI 10.1016/j.ijsolstr.2009.08. 007. URL http://dx.doi.org/10.1016/j.ijsolstr. 2009.08.007

37. Orduña, A., Lourenço, P.B.: Three-dimensional limit analysis of rigid blocks assemblages. Part I: Torsion failure on frictional interfaces and limit analysis formulation. International Journal of Solids and Structures 42(18-19), 5140-5160 (2005). DOI 10.1016/j.ijsolstr.2005.02.010. URL http://linkinghub.elsevier.com/retrieve/pii/ S0020768305000636

38. Orduña, A., Lourenço, P.B.: Three-dimensional limit analysis of rigid blocks assemblages. Part II: Loadpath following solution procedure and validation. International Journal of Solids and Structures 42(18-19), 5161-5180 (2005). DOI 10.1016/j.ijsolstr.2005.02.011. URL http://linkinghub.elsevier.com/retrieve/pii/ S0020768305000648

39. Papadopoulos, C., Basanou, E., Vardoulakis, I., Boulon, M., Armand, G.: Mechanical behaviour of Dionysos marble smooth joints under cyclic loading: II constitutive modelling. In: Proceedings of the international conference on mechanics of jointed and faulted rock. Vienna, Austria (1998)

40. Papantonopoulos, C., Psycharis, I.N., Papastamatiou, D.Y., Lemos, J.V., Mouzakis, H.P.: Numerical prediction of the earthquake response of classical columns using the distinct element method. Earthquake Engineering and Structural Dynamics 31(9), 1699-1717 (2002). DOI 10.1002/eqe. 185

41. Petry, S., Beyer, K.: Scaling unreinforced masonry for reduced-scale seismic testing. Bulletin of Earthquake Engineering pp. 1-25 (2014). DOI 10.1007/ s10518-014-9605-1

42. van der Pluijm, R.: Out-of-Plane Bending of Masonry Behaviour and Strength. Eindhoven: Technische Universiteit Eindhoven (1999). DOI 10.6100/IR528212

43. Restrepo-Vélez, L., Magenes, G., Griffith, M.: Dry Stone Masonry Walls in Bending - Part I: Static Tests. International Journal of Architectural Heritage 8(1), 1-28 (2014). DOI 10.1080/15583058.2012. 663059. URL http://www.tandfonline.com/doi/abs/ 10.1080/15583058.2012.663059

44. Rondelet, J.: Traité théorique et pratique de l'art de bâtir. Chez l'auteur, Paris (1834)

45. Salençon, J.: Calcul à la Rupture et Analyse Limite. Presses de l'Ecole Nationale des Ponts et Chaussées, Paris (1983)

46. Salerno, G., de Felice, G.: Continuum modeling of periodic brickwork. International Journal of Solids and Structures 46(5), 1251-1267 (2009). DOI 10.1016/j.ijsolstr. 2008.10.034. URL http://linkinghub.elsevier.com/ retrieve/pii/S0020768308004642

47. Simon, J., Bagi, K.: Discrete element analysis of the minimum thickness of oval masonry domes. International Journal of Architectural Heritage (2014). DOI
10.1080/15583058.2014.996921. URL http://dx.doi. org/10.1080/15583058.2014.996921

48. Stefanou, I., Fragiadakis, M., Psycharis, I.N.: Seismic Reliability Assessment of Classical Columns Subjected to Near Source Ground Motions. In: Seismic Assessment, Behavior and Retrofit of Heritage Buildings and Monuments, chap. 3, pp. 61-82. Springer (2015). DOI 10.1007/ 978-3-319-16130-3_3. URL http://link.springer.com/ 10.1007/978-3-319-16130-3\{_\}3

49. Stefanou, I., Psycharis, I., Georgopoulos, I.O.: Dynamic response of reinforced masonry columns in classical monuments. Construction and Building Materials 25(12), 4325-4337 (2011). DOI 10.1016/j.conbuildmat.2010.12. 042. URL http://dx.doi.org/10.1016/j. conbuildmat. 2010.12 .042

50. Stefanou, I., Sab, K., Heck, J.V.: Three dimensional homogenization of masonry structures with building blocks of finite strength: A closed form strength domain. International Journal of Solids and Structures 54, 258-270 (2015). DOI 10.1016/j.ijsolstr.2014.10.007. URL http://linkinghub.elsevier.com/retrieve/pii/ S0020768314003783

51. Stefanou, I., Sulem, J., Vardoulakis, I.: Threedimensional Cosserat homogenization of masonry structures: elasticity. Acta Geotechnica 3(1), 71-83 (2008). DOI 10.1007/s11440-007-0051-y. URL http://www. springerlink.com/index/10.1007/s11440-007-0051-y

52. Stefanou, I., Sulem, J., Vardoulakis, I.: Homogenization of interlocking masonry structures using a generalized differential expansion technique. International Journal of Solids and Structures 47(11-12), 1522-1536 (2010). DOI 10.1016/j.ijsolstr.2010.02.011. URL http://linkinghub. elsevier.com/retrieve/pii/S0020768310000533

53. Stefanou, I., Vardoulakis, I., Mavraganis, A.: Dynamic motion of a conical frustum over a rough horizontal plane. International Journal of Non-Linear Mechanics 46, 114 124 (2011). DOI 10.1016/j.ijnonlinmec.2010.07.008

54. Trovalusci, P., Pau, A.: Derivation of microstructured continua from lattice systems via principle of virtual works: the case of masonry-like materials as micropolar, second gradient and classical continua. Acta Mechanica (2013). DOI 10.1007/s00707-013-0936-9. URL http: //link. springer.com/10.1007/s00707-013-0936-9

55. Vannucci, P., Masi, F., Stefanou, I.: A study on the simulation of blast actions on a monument structure (2017). URL https://hal.archives-ouvertes.fr/ hal-01447783. Working paper or preprint 